\title{
Uma proposta pedagógico- variacionista para trabalhar a transposição do apagamento do /r/ da fala para a escrita com alunos da EJA ${ }^{1}$
}

\author{
A pedagogical-variacionist \\ proposal to work for the \\ transposition of the writing of the \\ a / $r$ / da talk to the writing with \\ students of the EJA
}

Suely Cláudia Lobato Maciel
https://orcid.org/0000-0001-6050-7944

Dircel Aparecida Kailer https://orcid.org/0000-0002-4387-2066

Resumo: Este estudo visa propor atividades pedagógicas que auxiliem os professores de Língua Portuguesa a trabalharem o não registro da consoante $-\mathrm{R}$ em coda silábica, com alunos da EJA. Busca-se, também, identificar os contextos linguísticos e extralinguísticos que possam favorecer a ocorrência desse processo linguístico. Com base nos pressupostos das Sociolinguísticas Variacionista (LABOV, 1972) e Educacional (BORTONI-RICARDO, 2004), analisou-se dados orais e escritos obtidos, respectivamente, através do projeto ALiB e de textos escritos de alunos

\footnotetext{
${ }^{1}$ Este artigo apresenta dados coletados para a elaboração de minha dissertação de mestrado, intitulada: $O$ Apagamento do -R em Coda Silábica em Textos Escritos por Alunos da EJA de Belém do Pará: uma proposta de intervenção pedagógico-variacionista, defendida em 20/12/2018 pelo Programa de Mestrado Profissional em Letras (ProfLetras), na Universidade Estadual de Londrina (UEL).

${ }^{2}$ Universidade Estadual de Londrina. E-mail: suelylobato@gmail.com

${ }^{3}$ Universidade Estadual de Londrina. E-mail: ueldircel@hotmail.com
} 
de Belém do Pará. O não registro de $-\mathrm{R}$ em coda silábica externa é uma transposição do apagamento dessa consoante na fala da comunidade investigada. Após as atividades propostas, o uso da variante foi significativamente menor nas produções analisadas.

Palavras-Chave: EJA; Apagamento do /R/; Escrita; Sociolinguística.

\begin{abstract}
This study aims to propose pedagogical activities that will help Portuguese-speaking teachers to work on the non-registration of the consonant - $\mathrm{R}$ in syllable coda, with EJA students. It also seeks to identify the linguistic and extralinguistic contexts that may favor the occurrence of this linguistic process. Based on the assumptions of Sociolinguistic Variation (LABOV, 1972) and Educational (BORTONI-RICARDO, 2004), we analyzed oral and written data obtained, respectively, through the $\mathrm{ALiB}$ project and written texts of students from Belém do Pará. The non-registration of $-\mathrm{R}$ in external syllabic coda is a transposition of the deletion of this consonant in the speech of the community investigated. After the proposed activities, the use of the variant was significantly lower in the analyzed productions.
\end{abstract}

Keywords: EJA; Deleting /R/; Writing; Sociolinguística.

\title{
Introdução
}

O apagamento ou apócope do /R/ em coda silábica na oralidade é um processo fonológico que vem despertando grande interesse em autores de áreas como Fonética, Fonologia e Sociolinguística. Os contextos linguísticos e extralinguísticos que favorecem sua implementação também vêm sendo objetos de estudos (CALLOU et al., 1998; MONARETTO, 2000; AGUILERA, KAILER, 2015; ALMEIDA, E. F., KAILER, 2015; entre outros).

A ocorrência desse processo no falar de moradores de Belém do Pará, localidade alvo desta pesquisa, já foi investigada no Projeto Atlas Linguístico do Brasil (ALiB). A equipe do projeto demonstra, nas cartas produzidas, que o apagamento chega a $75 \%$ das possibilidades na capital paraense.

Contudo, o não registro da consoante -R em coda silábica externa em textos escritos é um fenômeno linguístico ainda pouco estudado no português do Brasil (PB). Gurjel (2016), por exemplo, analisou a incidência desse processo em verbos no infinitivo em textos de alunos do $8^{\circ}$ ano de uma escola estadual de Caraúbas, Rio Grande do Norte. A autora verificou que o não registro de $-R$ na escrita dos educandos segue os parâmetros do apagamento dessa consoante na oralidade.

Almeida D.C. (2016), por sua vez, investigou tanto o não registro de -R quanto sua indevida inserção como hipercorreção em textos escritos de alunos do $8^{\circ}$ ano em Fortaleza, Ceará. A pesquisadora constatou que esse erro ortográfico se deve à transposição de marcas da oralidade. 
Ambos os trabalhos são recentes, pois foram realizados para o Mestrado Profissional em Letras (ProfLetras), um programa nacional com pouco mais de cinco anos de existência. São pesquisas voltadas para alunos do ensino regular, dentro da relação idade/série. Isto é, não abrangem a Educação de Jovens e Adultos (EJA).

Sendo assim, este estudo busca propor atividades pedagógicas que auxiliem os professores de Língua Portuguesa a trabalhar a transposição do apagamento do rótico em coda externa da oralidade para a escrita, com alunos da EJA. A carência de pesquisas que unam variação linguística e essa modalidade de ensino justifica a realização deste trabalho enquanto contribuição não somente para os estudos fonético-fonológicos e sociolinguísticos do PB, como para a abertura das salas de aula à existência da variação linguística.

\section{Pressupostos teórico-metodológicos}

Este estudo baseia-se nos pressupostos teórico-metodológicos da Sociolinguística Variacionista Laboviana (LABOV, 1972) e da Sociolinguística Educacional (BORTONIRICARDO, 2004). É caracterizado como uma pesquisa-ação, compreendida aqui como:

[...] um tipo de pesquisa social com base empírica que é concebida e realizada em estreita associação com uma ação ou com a resolução de um problema coletivo e no qual os pesquisadores e os participantes representativos da situação ou do problema estão envolvidos de modo cooperativo ou participativo. (THIOLLENT, 2000, p. 14) 
O trabalho foi elaborado a partir do diagrama de análise e diagnose de erros proposto por Bortoni-Ricardo (2005).

Fig. 1: Diagrama de Análise e Diagnose de Erros

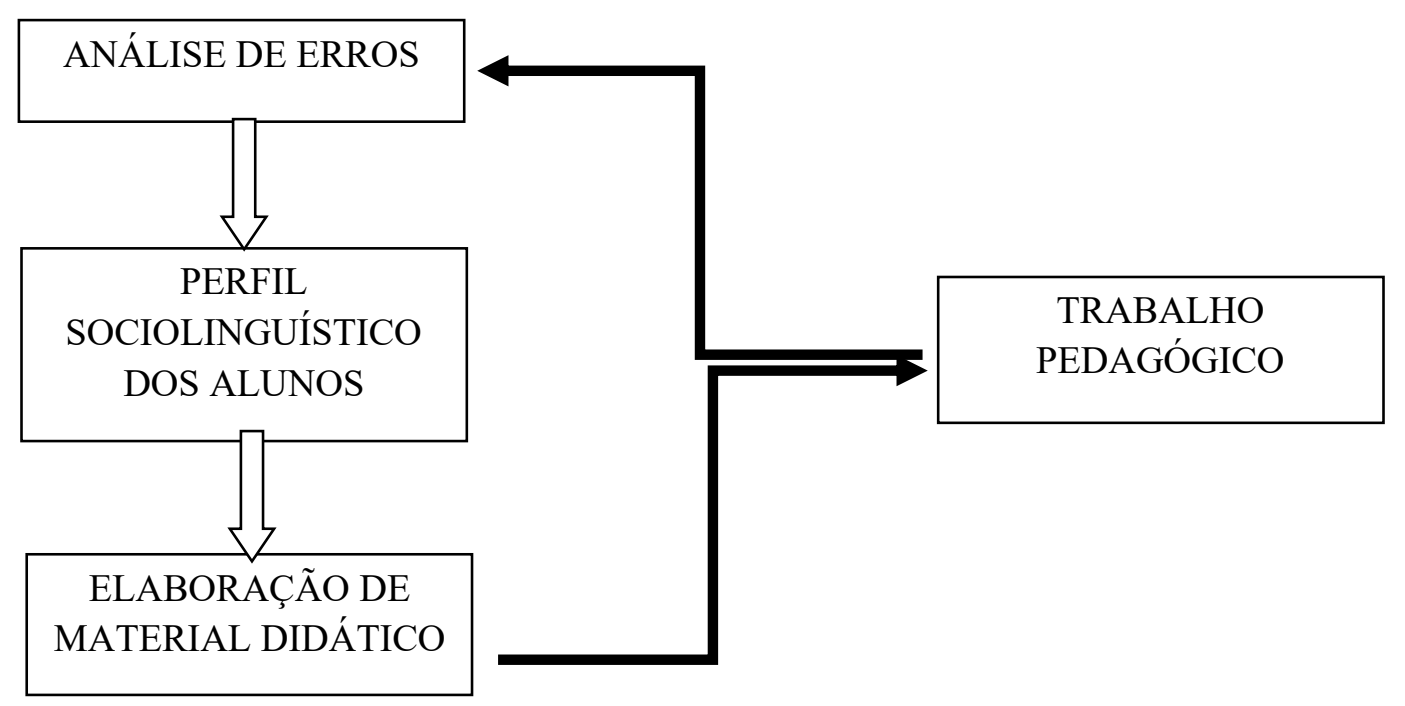

Fonte: Bortoni-Ricardo (2005, p. 59)

Com base na proposta da autora, analisou-se 31 textos escritos por educandos do Ensino Fundamental (EF) II, na modalidade da EJA, de uma escola pública de Belém do Pará, sendo 16 alunos da $3^{\text {a }}$ Totalidade $^{4}$ e 15 alunos da $4^{\text {a }}$ Totalidade. Detectou-se, por essa análise, uma grande frequência do não registro da consoante $-\mathrm{R}$ em coda silábica externa (como em: compraØ roupas, consigo entende Ø o, o celulaØ caiu, por exemplo, em que o símbolo Ø marca o não registro da consoante). Iniciou-se, então, o trabalho da professora pesquisadora para auxiliar seus alunos a refletirem sobre a existência da variação linguística, a valorizarem as variedades populares por eles utilizadas, e a se conscientizarem da necessidade de apropriação das variantes socialmente prestigiadas para que pudessem utilizá-las sempre que necessário.

A hipótese, neste trabalho, para o não registro da consoante é que esteja havendo uma transposição da fala para a escrita, ou seja, grafa-se tal qual se pronuncia. Acredita-se que por, em Belém, a variante predominante em coda silábica ser a glotal [h], a qual, por sua aspiração, torna-se pouco perceptível no referido contexto, os usuários tenderiam a não registrá-la no

${ }^{4}$ A Secretaria Municipal de Educação de Belém (SEMEC) trabalha com a EJA na forma de Totalidades ( $1^{\mathrm{a}}$ à $4^{\mathrm{a}}$ ). A $3^{\mathrm{a}}$ Totalidade equivale aos $6^{\circ}$ e $7^{\circ}$ anos, e a $4^{\mathrm{a}}$ Totalidade, aos $8^{\circ}$ e $9^{\circ}$ anos do EF Regular. 
momento da grafia. Para que tal hipótese pudesse ser comprovada, analisou-se dados orais coletados na capital paraense pela equipe do Projeto ALiB (COMITÊ, 2001) com quatro informantes com a mesma faixa de escolaridade dos alunos das turmas investigadas. Desses dados, foram recortadas, por meio do programa SoundForge (2011), as ocorrências que possibilitavam a realização do /R/ em coda externa. Após o recorte, os dados foram codificados quanto aos contextos linguísticos (classe morfológica, extensão do vocábulo, vogal da sílaba alvo, ponto e modo de articulação) e extralinguísticos (sexo, faixa etária e estilo de produção de fala). Terminada a codificação, os dados foram submetidos à análise probabilística no Programa Goldvarb $\mathrm{X}$, que forneceu os resultados em percentual e em peso relativo ${ }^{5}$, conforme apresentados a seguir.

\section{Dados da oralidade em Belém do Pará}

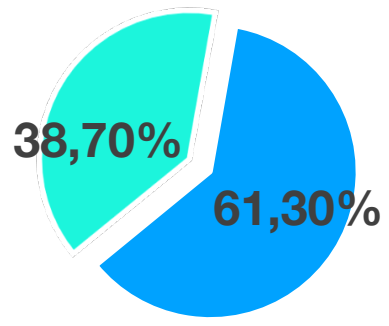

\section{- Apagamento de /R/ \\ - Realização de /R/}

Fonte: Elaborado pela autora com base nos dados orais do ALiB.

De acordo com os dados apresentados no Gráfico 1, percebe-se que a quantidade de apagamentos do rótico em coda externa (61,30\%) é superior a de realizações $(38,70 \%)$. Isso comprova a hipótese levantada de que, na oralidade, a apócope do /R/ em coda externa já faz parte da norma culta urbana belenense. Entre os contextos mais favoráveis à aplicação da

\footnotetext{
${ }^{5}$ Os valores dos pesos relativos devem ser lidos da seguinte forma: quanto mais próximos de 0 , menos favoráveis à aplicação da regra variável; quanto mais próximos de 1, mais favoráveis. Se estiverem próximos a 0,5, significa que o fator em análise é neutro quanto à aplicação ou não da regra em análise, no caso deste estudo, do apagamento do /R/ em coda silábica externa.
} 
variável estão: o estilo de produção de fala, com o relato sendo o estilo mais favorável; a classe morfológica, com os verbos sendo mais favoráveis que os não-verbos; e a extensão silábica, com as palavras polissílabas sendo mais suscetíveis ao apagamento.

Após a análise dos dados orais, realizou-se o mesmo processo nos 31 textos escritos por alunos da EJA. Aplicou-se, também, um questionário sociocultural baseado no modelo utilizado no projeto ALiB, para compreender o perfil sociolinguístico dos educandos. Depois da submissão dos dados ao programa Goldvarb X, chegou-se aos seguintes resultados.

Gráfico 2: Não Registro de - R em Coda Silábica Externa em Belém do Pará

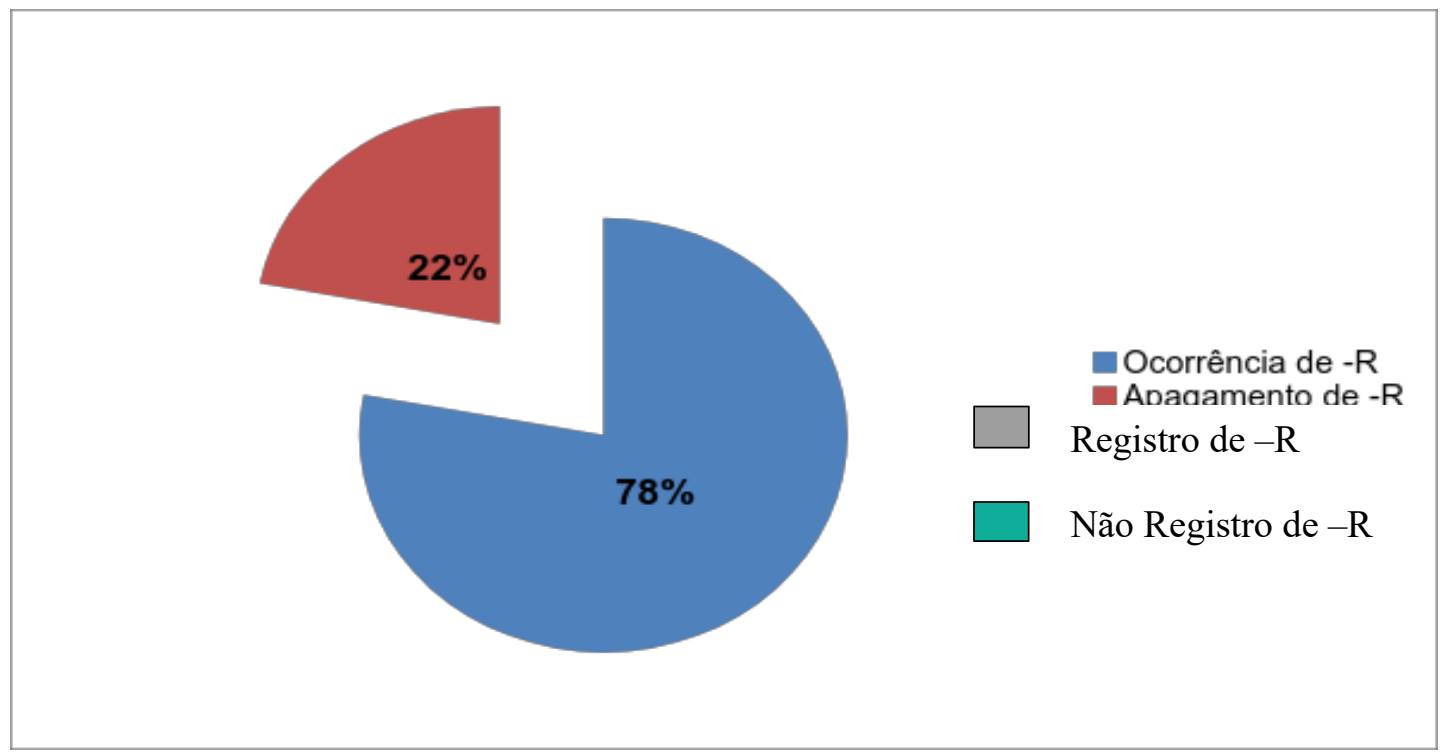

Fonte: Elaborado pela autora com base nos textos escritos de alunos da EJA.

A partir da análise dos dados apresentados no Gráfico 2, pode-se perceber que o percentual de registros da consoante $-\mathrm{R}$ é significativamente maior que o de não registros. No entanto, por serem dados coletados de textos escritos em uma situação formal de comunicação (um trabalho produzido em sala de aula), que exige um maior grau de monitoramento da linguagem, considera-se um percentual significativo.

Para compreender melhor como esse processo efetiva-se na escrita, realizou-se uma análise dos contextos linguísticos (classe morfológica e vogal da sílaba alvo) e extralinguísticos (sexo, faixa etária, anos de escolarização, local de origem, etapa da EJA). Essa análise será demonstrada conforme o grau de relevância apresentado pelo programa Goldvarb X. 
Quadro 1: Atuação das Variáveis Linguísticas para a Implementação da Variante Não Registro de -R

\begin{tabular}{|c|c|c|c|c|}
\hline \multicolumn{2}{|c|}{ VARIÁVEIS } & $\begin{array}{c}\text { TOTAL/ } \\
\text { APAGAM. }\end{array}$ & $\begin{array}{c}\text { PERC. DE } \\
\text { APAG. }\end{array}$ & $\begin{array}{c}\text { PESO } \\
\text { REL. }\end{array}$ \\
\hline \multirow{2}{*}{$\begin{array}{c}\text { CLASSE } \\
\text { MORFOLÓGICA }\end{array}$} & VERBO & $220 / 56$ & $25.5 \%$ & 0.579 \\
\cline { 2 - 5 } & NÃO VERBO & $57 / 04$ & $7 \%$ & 0.227 \\
\hline \multirow{3}{*}{ NÚCLEO DA SÍLABA } & A & $123 / 42$ & $34.1 \%$ & 0.693 \\
\cline { 2 - 5 } ALVO & $\mathrm{E}$ & $86 / 13$ & $15.1 \%$ & 0.354 \\
\cline { 2 - 5 } & $\mathrm{I}$ & $30 / 03$ & $10 \%$ & 0.265 \\
\cline { 2 - 5 } & $\mathrm{O}$ & $38 / 02$ & $5.3 \%$ & 0.386 \\
\hline
\end{tabular}

Fonte: Elaborado pela autora com base nos textos escritos de alunos da EJA.

Considerando-se os dados apresentados no Quadro 1, pode-se chegar à seguinte análise:

a) No que tange à classe morfológica, os resultados vão ao encontro dos observados em relação aos dados da oralidade na capital do Pará e aos resultados apresentados nos estudos de Aguilera e Kailer (2015). Ou seja, o não registro de -R ocorre com mais frequência em verbos do que em nomes. Pensamento que já foi comprovado por outros estudos, como o de Ribeiro (2013), que afirma ser a transposição do apagamento do rótico da oralidade para a escrita muito mais frequente em verbos do que em não verbos.

b) Em relação à vogal da sílaba alvo, pode-se perceber que a vogal baixa (a) é mais favorável ao não registro de $-\mathrm{R}$ do que as demais. Considerando a interferência da oralidade na escrita, a variante ocorre mais em sílabas formadas pela vogal baixa por acomodação articulatória. Seria mais trabalhoso para o falante, após pronunciar a vogal central [a], ter de pronunciar uma consoante glotal [h] (variante utilizada em Belém para o rótico em coda silábica). 
Quadro 2: Atuação das Variáveis Extralinguísticas para a Implementação da Variante Não Registro de -R

\begin{tabular}{|c|c|c|c|c|}
\hline \multicolumn{2}{|c|}{ VARIÁVEIS } & TOTAL/ & PERC. DE & PESO \\
\hline \multirow[t]{2}{*}{ SEXO } & FEMININO & $172 / 41$ & $23.3 \%$ & 0.587 \\
\hline & MASCULINO & $105 / 20$ & $19 \%$ & 0.360 \\
\hline \multirow[b]{2}{*}{ FAIXA ETÁRIA } & 1 (15 A 20 ANOS) & $134 / 33$ & $24.6 \%$ & 0.728 \\
\hline & 2 (MAIOR DE 20 ANOS) & $143 / 27$ & $18.9 \%$ & 0.285 \\
\hline \multirow{2}{*}{$\begin{array}{l}\text { LOCAL DE } \\
\text { ORIGEM }\end{array}$} & CAPITAL & $192 / 44$ & $22.9 \%$ & 0.573 \\
\hline & INTERIOR & $85 / 16$ & $18.8 \%$ & 0.339 \\
\hline \multirow{4}{*}{$\begin{array}{c}\text { TEMPO SEM } \\
\text { ESTUDAR }\end{array}$} & SEMPRE ESTUDOU & $120 / 31$ & $25.8 \%$ & 0.418 \\
\hline & 2 A 5 ANOS & $54 / 07$ & $13 \%$ & 0.405 \\
\hline & 6 A 10 ANOS & $25 / 04$ & $16 \%$ & 0.471 \\
\hline & MAIS DE 10 ANOS & $60 / 18$ & $30 \%$ & 0.742 \\
\hline \multirow{2}{*}{$\begin{array}{l}\text { ETAPA DE } \\
\text { ENSINO }\end{array}$} & $3^{\text {a }}$ TOTALIDADE & $117 / 26$ & $22.2 \%$ & \\
\hline & $4^{\mathrm{a}}$ TOTALIDADE & $160 / 34$ & $21.2 \%$ & \\
\hline
\end{tabular}

Fonte: Elaborado pela autora com base nos textos escritos de alunos da EJA.

A análise dos dados apresentados no Quadro 2 demonstra que:

a) O sexo feminino favorece a implementação da variante não registro de $-R$. Considerando o pensamento de Labov (1972) de que há uma tendência de as mulheres evitarem as construções estigmatizadas e privilegiarem as formas de prestígio, conclusão a que também chegaram outros estudos acerca da variação (MOLLICA, PAIVA, PINTO, 1989; SCHERRE, 1996, entre outros), pode-se supor que, se as mulheres estão usando a variante não registro de $-R$, ela não é vista de forma desprestigiada na comunidade investigada. 
b) A faixa etária 1 (pessoas entre 15 e 20 anos) é bastante favorável para a implementação da variante em estudo (0.728), especialmente se comparado com a faixa etária 2 (pessoas acima de 20 anos) que possui um peso relativo bem menor (0.285).

Tal análise encontra respaldo, ainda, no estudo feito por Naro (2012), que demonstra a preferência das pessoas mais velhas por formas mais antigas, e dos jovens pelas variantes inovadoras. Essa preferência também vem ocorrendo em relação ao apagamento do rótico na oralidade.

c) A variável local de origem conduz igualmente à hipótese de que tal variante não é vista de forma estigmatizada pela comunidade investigada. Os informantes nascidos em Belém, capital do Pará, não registram o segmento - $\mathrm{R}$ em coda silábica de forma mais frequente do que aqueles nascidos no interior do estado. O que vai de encontro à afirmação de Bortoni-Ricardo (2005) de que, dentro do continuum rural-urbano, os vernáculos rurais são mais estigmatizados (por sua origem influenciada pelo tupi e pelo pidgin das comunidades escravas), enquanto os vernáculos urbanos são socialmente prestigiados (por sua origem mais próxima à língua trazida pelos colonizadores).

d) As pessoas com mais de 10 anos sem estudar não registram o rótico em coda silábica com mais frequência do que as outras categorias analisadas. Essa comprovação vem ao encontro das hipóteses levantadas neste estudo, quando se pressupôs que um tempo considerável fora do ensino formal poderia comprometer a competência linguística do informante em situações monitoradas de uso da língua.

No entanto, o que chama atenção, nos dados apresentados, é que o peso relativo dos informantes que sempre estudaram (embora estejam em uma situação de distorção idade/série e por isso frequentem a EJA) é muito próximo daqueles que, por qualquer período de tempo analisado, ficaram fora do ensino formal. Podendo-se inferir que, por se tratar de um erro advindo de um traço gradual (conforme postula Bortoni-Ricardo (2005), os erros decorrentes de regras fonológicas graduais podem ocorrer também entre falantes da língua culta), a escola pode não estar trabalhando com os alunos as possibilidades de uso dessa variação. Isto é, os educandos não estão sendo instrumentalizados para o uso concreto da língua nas diversas situações de comunicação com as quais terão contato ao longo da vida.

e) A variável etapa de ensino não foi selecionada pelo programa Goldvarb X como relevante para a implementação da variante não registro de $-R$. No entanto, ela aparece no Quadro 2 devido à importância que Ihe fora atribuída pela professora pesquisadora. O percentual de não registro de $-R$ de quem está na $3^{\text {a }}$ Totalidade, ou seja, iniciando o EF II, e o de quem está na $4^{\text {a }}$ Totalidade, isto é, concluindo essa etapa de ensino, é muito próximo. Essa 
análise leva mais uma vez à conclusão de que a escola não vem trabalhando de forma consistente esse aspecto da variação linguística com os educandos.

Tão importante quanto a percepção e a comprovação de uma dificuldade apresentada por alunos em sala de aula, é a decisão do que fazer para ajudá-los a superar tal dificuldade. Após toda a análise aqui detalhada, iniciou-se o processo de elaboração e implementação de atividades pedagógicas. Essas atividades foram pensadas para trabalhar com os alunos a percepção e compreensão do que seja a variação linguística e das possibilidades de uso da língua nos vários contextos em que estão socialmente inseridos, enfatizando o registro e o não registro do rótico em coda silábica externa.

\section{Atividades pedagógicas propostas}

Partindo-se da coleta e análise de dados linguísticos obtidos nos textos escritos, comparando tal análise com os dados orais do Projeto ALiB e com o perfil sociolinguístico dos alunos, que forneceram os dados extralinguísticos, pôde-se chegar a seguinte diagnose:

a) A comparação dos dados da fala com os da escrita demonstra que, de fato, o não registro da consoante $-R$ em coda silábica externa em textos escritos ocorre pela transposição desse apagamento da fala dos usuários. Em outras palavras, o aluno escreve tal qual pronuncia.

b) Apesar da diferença de aplicação para coleta de dados, pôde-se perceber que o apagamento, na fala, e o não registro, na escrita, seguem padrões muito parecidos.

c) Há uma porcentagem significativa de não registros da consoante $-R$ em textos escritos monitorados, o que por si só já deve ser motivo de uma intervenção pedagógica que trabalhe o contínuo de monitoramento estilístico.

d) As mulheres estão deixando mais de registrar o $-R$ do que os homens, o que leva a hipótese de que não se trata de uma variante estigmatizada entre a comunidade investigada.

e) Os jovens estão utilizando mais o não registro, o que pressupõe uma mudança linguística em andamento.

f) Os alunos que sempre viveram na capital não registram o - $R$ com mais frequência do que aqueles que vieram do interior, o que comprova que tal processo, na fala, já faz parte da linguagem urbana comum.

g) Os educandos que ficaram um longo período de tempo longe do ensino formal utilizam mais o não registro do rótico. 
h) Os verbos no infinitivo são muito mais suscetíveis ao não registro do -R do que os nomes, especialmente os que são da primeira conjugação, com a vogal baixa (a) como núcleo da sílaba alvo.

i) Por fim, as atividades aqui apresentadas devem ser trabalhadas tanto com alunos que estejam ingressando no EF II quanto com os que estejam concluindo essa etapa de ensino, uma vez que a porcentagem de não registros em ambos os casos foi muito parecida.

A partir de tal diagnose e buscando contribuir para uma melhor produção escrita desses alunos em contextos monitorados, foram propostas as seguintes atividades.

Atividade 1: Que som o R tem?

Objetivo: Mostrar aos alunos, de maneira prática e lúdica, as diferentes formas de pronúncia do rótico, em coda externa, nas regiões do Brasil. Essa percepção auxiliou na compreensão de que $\mathrm{o} / \mathrm{R} /$ final pode ser realizado de diversas formas sem, contudo, modificar sua função na palavra, servindo, inclusive, como marca regional, não havendo uma pronúncia melhor ou pior. Ajudou, ainda, no combate a preconceitos existentes com determinadas realizações, como o retroflexo \\(ALMEIDA, E. F.; KAILER, 2016). Foi importante, também, para a percepção de que as pronúncias glotal $/ \mathrm{h} /$ e velar $/ \mathrm{X} /$ são mais fáceis de sofrerem apagamento por serem menos perceptíveis do que o tepe /r/ ou o próprio retroflexo / $\_/$, por exemplo.

Desenvolvimento:

* Distribuir, para os alunos, cartas (Anexo A) que identifiquem as realizações do /R/ e solicitar que as levantem, de acordo com o que perceberem nos áudios apresentados. A ideia não é ensinar a nomenclatura atribuída a cada realização, mas auxiliar os alunos a compreenderem que algumas são mais fortes, outras mais fracas, e outras canceladas;

* Ouvir áudios (recortados do projeto ALiB) de pessoas pronunciando as várias formas do rótico, e identificando suas regiões;

* Sortear o nome de um estado brasileiro e fazer a leitura de um texto escrito, de acordo com a pronúncia desse respectivo estado;

* Comentar acerca desse e de outros exemplos da variação que ocorre no Brasil;

* Ressaltar que tal variação é uma marca linguística desses grupos, assim como as gírias e algumas expressões.

Atividade 2: Bingo Ortográfico

Objetivo: Perceber visualmente a grafia de verbos e nomes com -R em coda silábica externa, bem como comparar a fala de quem "cantou" a pedra (palavra) e a realização escrita desta. 
Desenvolvimento:

* Distribuir, aos alunos, cartelas (Anexo B) com várias palavras grafadas com -R em coda silábica;

* Fazer circular pela turma uma caixa contendo todas essas palavras, para que cada aluno sorteie uma e "cante" para os demais;

* Vence o jogo quem completar primeiro a cartela;

* Após a brincadeira, deve-se comentar acerca da grafia das palavras e da pronúncia de quem "cantou" as pedras/palavras.

Atividade 3: Tem /R/ aqui?

Objetivo: Fazer com que os alunos percebessem se os cantores pronunciam ou não o /R/ em coda silábica em músicas apresentadas.

Desenvolvimento:

* Exibir o clipe de três músicas, acompanhando o áudio com a leitura da letra oficial;

* Comparar os textos escritos com as pronúncias dos cantores, observando a realização ou o apagamento do /R/.

Atividade 4: Gincana: quem encontra mais?

Objetivo: Proporcionar aos alunos uma percepção visual das palavras grafadas com -R em coda silábica. A partir de uma competição entre grupos, os educandos buscaram em vários textos escritos (jornais, revistas, folders, encartes etc.) o maior número possível de palavras terminadas com o rótico.

Desenvolvimento:

* Formar grupos de 3 a 5 alunos;

* Distribuir para os grupos: revistas, jornais, folders, encartes, entre outros textos que circulam no seu cotidiano;

* Orientar os alunos para que encontrem, recortem e colem em uma folha de papel 40 kg, o maior número de palavras grafadas com -R em coda silábica.

Atividade 5: Qual é o significado?

Objetivo: Fazer com que os alunos explicassem o significado de um par de palavras, no qual uma estava grafada com o rótico em coda externa e a outra não, por exemplo: "amar" e "ama". Os educandos puderam perceber, assim, que o não registro do $-\mathrm{R}$ pode modificar o sentido do que se quer dizer. 
Desenvolvimento:

* Cada aluno sorteará uma ficha que conterá um par de palavras para as quais ele deverá encontrar uma forma de explicar os significados, o que pode acontecer através de exemplos, do uso do dicionário, ou de outra forma que ele apresente.

Atividade 6: Como eu diria?

Objetivo: Fazer com que, a partir de tudo o que foi discutido até então, os alunos utilizassem as palavras da atividade anterior para transmitir uma mensagem em duas situações distintas: uma que não exigisse um monitoramento estilístico, e outra em que esse monitoramento fosse necessário. Os educandos puderam perceber, assim, que um texto menos monitorado nem sempre é adequado à situação comunicativa, assim como o mais monitorado também é inadequado em alguns contextos.

Desenvolvimento:

* Utilizando as palavras sorteadas, os alunos devem produzir e apresentar quatro textos: dois orais e dois escritos, em situações comunicativas que variem o grau de monitoramento estilístico necessário (uma conversa entre amigos, um telefonema para seu chefe, um comentário no Facebook e uma carta de apresentação, por exemplo).

\section{Análise da segunda produção textual}

Após o desenvolvimento das atividades anteriormente detalhadas, os alunos das turmas investigadas tiveram a oportunidade de reescrever seus textos. Assim como a primeira produção, esses textos foram analisados, recortando-se todas as palavras que deveriam ser grafadas com $\mathrm{R}$ em coda silábica externa. Após esse recorte, utilizou-se novamente o programa Goldvarb X para verificar a porcentagem de registros e de não registros do rótico. No gráfico 3, demonstramse os resultados dessa análise. 


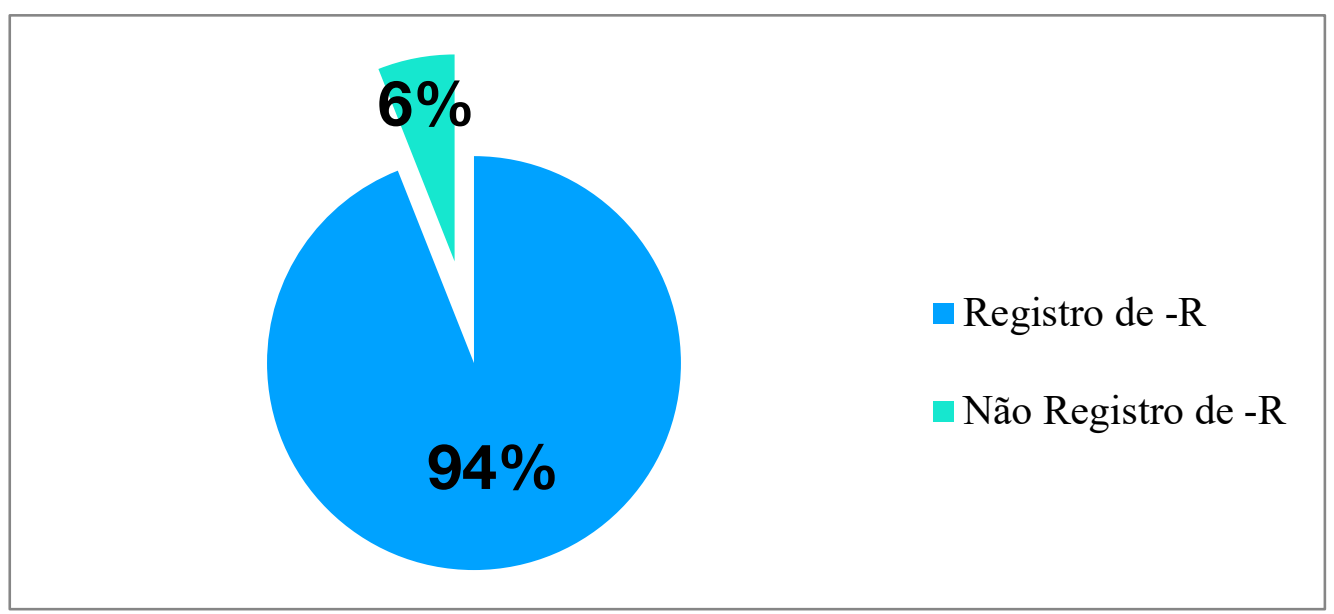

Fonte: Elaborado pela autora com base na $2^{\mathrm{a}}$ produção escrita dos alunos.

O percentual de uso da variante não registro de $-R$, apresentado no Gráfico 3, demonstra que as atividades pedagógicas desenvolvidas com as turmas foram significativas para alcançar os objetivos propostos neste trabalho. Somente em $6 \%$ das possibilidades de grafia do rótico, ele não foi registrado. Isso evidencia um amadurecimento linguístico dos alunos no sentido de corrigir a ortografia das palavras, adequando seu texto ao contexto de produção.

Das 164 possibilidades de uso do -R em coda silábica externa, ele não foi registrado em apenas 10. No quadro a seguir, demonstra-se como esses não registros estão distribuídos em relação aos fatores linguísticos investigados.

Quadro 3 - Distribuição do Uso da Variante Não Registro de -R em Relação aos Fatores Linguísticos, nos Dados da $2^{\text {a }}$ Produção Textual

\begin{tabular}{|c|c|c|}
\hline \multicolumn{2}{|c|}{ Fatores Linguísticos } & Quantidade de Não Registros \\
\hline Classe Morfológica & Verbos & 10 \\
\cline { 2 - 3 } & Não Verbos & 0 \\
\hline \multirow{3}{*}{ Vogal da Sílaba Alvo } & $\mathrm{A}$ & 1 \\
\cline { 2 - 3 } & $\mathrm{E}$ & 0 \\
\cline { 2 - 3 } & $\mathrm{I}$ & 0 \\
\cline { 2 - 3 } & O & 9 \\
\hline
\end{tabular}

Fonte: Elaborado pela autora com base nos dados da $2^{\text {a }}$ produção textual. 
Os dados apresentados no quadro 3 demonstram que, de fato, os verbos, especialmente os da primeira conjugação, são muito mais suscetíveis ao não registro de $-\mathrm{R}$ do que os não verbos. Essa confirmação corrobora com os dados apresentados na análise dos textos de primeira produção. Embora as atividades de intervenção tenham sido significativas para a diminuição dos eventos de não registro do rótico, as que voltaram a ocorrer foram $100 \%$ em verbos.

Em relação aos fatores extralinguísticos, a análise das segundas produções também corrobora com o que foi percebido nas primeiras, conforme demonstrado no quadro 4.

Quadro 4 - Distribuição do Uso da Variante Não Registro de -R em Relação aos Fatores Extralinguísticos, nos Dados da $2^{a}$ Produção Textual

\begin{tabular}{|c|c|c|}
\hline \multicolumn{2}{|c|}{ Fatores Extralinguísticos } & Quantidade de Não Registros \\
\hline \multirow[t]{2}{*}{ Sexo } & Feminino & 6 \\
\hline & Masculino & 4 \\
\hline \multirow[t]{2}{*}{ Faixa Etária } & 1 (15 a 20 anos) & 7 \\
\hline & 2 (mais de 20 anos) & 3 \\
\hline \multirow[t]{2}{*}{ Origem } & Capital & 8 \\
\hline & Interior & 2 \\
\hline \multirow{4}{*}{$\begin{array}{c}\text { Tempo Fora da } \\
\text { Escola }\end{array}$} & Sempre Estudou & 2 \\
\hline & 1-5 anos & 4 \\
\hline & 6-10 anos & 2 \\
\hline & Mais de 10 anos & 2 \\
\hline \multirow[t]{2}{*}{ Etapa de Ensino } & $3^{\text {a }}$ Totalidade & 3 \\
\hline & $4^{\text {a }}$ Totalidade & 7 \\
\hline
\end{tabular}

Fonte: Elaborado pela autora com base nos dados da $2^{a}$ produção textual.

A análise dos dados da segunda produção textual, em relação aos fatores extralinguísticos investigados, confirma as conclusões chegadas após a primeira produção: as mulheres, os jovens e as pessoas nascidas na capital continuam não registrando mais o rótico em coda silábica externa. Essa resistência, embora com um número consideravelmente menor de ocorrências em relação à primeira análise, provavelmente se deva ao fato de o não registro de $-R$ não ser estigmatizado na comunidade de fala em questão. 


\section{Considerações finais}

Neste trabalho, a partir da proposta de análise e diagnose de erros pautada na Sociolinguística Educacional (BORTONI-RICARDO, 2005), buscou-se identificar as principais dificuldades apresentadas por alunos de turmas de $3^{\mathrm{a}}$ e $4^{\mathrm{a}}$ Totalidades da EJA, de Belém do Pará, no que tange à grafia das palavras. O não registro de $-\mathrm{R}$ em coda silábica externa foi o erro ortográfico mais recorrente, justificando a escolha desse processo para ser trabalhado com as referidas turmas. Tratou-se de uma pesquisa de caráter intervencionista (pesquisa-ação), que propôs atividades para auxiliar os alunos na percepção de que tal processo é inadequado na modalidade escrita, especialmente em contextos mais monitorados.

A análise dos fatores linguísticos e extralinguísticos que favorecem a implementação da variante em estudo foi importante para a elaboração das atividades pedagógicas de intervenção. Através dela, percebeu-se que a variante não registro de $-R$ não é vista de forma estigmatizada pela comunidade de fala investigada. Percebeu-se, também, que a escola não vem propondo atividades que instrumentalizem os alunos em relação ao uso ou não da variante, provavelmente por esta não ser marcada na fala.

Após o desenvolvimento das atividades, houve um significativo amadurecimento linguístico dos alunos no sentido de (re)pensar seu texto em relação ao contexto de produção. Esse (re)pensar inclui a preocupação com a grafia das palavras, facilitando a leitura do interlocutor. Em relação ao não registro de $-R$ em coda silábica, objeto de estudo deste trabalho, houve uma diminuição de $22 \%$ para $6 \%$, o que representa um avanço significativo. No entanto, duas observações feitas durante a análise da segunda produção textual chamam bastante atenção:

$1^{\text {a) }) ~ H o u v e ~ u m ~ n u ́ m e r o ~ m e n o r ~ d e ~ p o s s i b i l i d a d e s ~ d e ~ a n a ́ l i s e ~(f o r a m ~} 277$ possibilidades na primeira produção, e somente 164 na segunda) . Isto é, alguns alunos optaram por utilizar palavras que não possuíam $-\mathrm{R}$ em coda, em detrimento as que assim deveriam ser grafadas. Acredita-se que essa escolha se deveu ao receio de escrever incorretamente a palavra, uma vez que os educandos já estavam conscientes de que o não registro era objeto das atividades desenvolvidas.

$2^{\mathrm{a})}$ Ocorreram três casos de hipercorreção. Ou seja, palavras que não são escritas com -R em coda silábica, foram grafadas com o rótico (eu decidir enfrentar, eu nunca desistir de nada e eu conseguir falar com ela).

Ambas as observações comprovam o que foi dito: os alunos passaram, após a implementação das atividades, a pensar antes de escrever. Embora cometendo equívocos, 
percebe-se o amadurecimento do produtor textual, o qual possui conhecimento da estrutura de sua língua e tenta utilizar esse conhecimento na sua produção.

A análise dos dados da segunda produção textual, presente nos quadros 3 e 4, comprova o que foi percebido nos primeiros textos em relação aos fatores condicionantes, tanto linguísticos quanto extralinguísticos. E demonstra, também, que novas atividades precisarão ser desenvolvidas para que, cada vez mais, os alunos possam desvincular sua escrita de uma representação da fala, percebendo-as como modalidades distintas da língua.

Conclui-se com a certeza de que é preciso repensar a prática docente e o papel da escola, principalmente no que tange ao preconceito com as variantes populares do PB. Levar o acesso às variedades cultas da língua, respeitando o vernáculo do aluno, seja, talvez, um dos grandes desafios do ensino de língua materna.

\section{Referências}

AGUILERA, Vanderci de Andrade; KAILER, Dircel Aparecida. /R/ em coda silábica no Sul do Brasil: um estudo preliminar. In: KRAGH, Kirsten A. Jeppesen; LINDSCHOUW, Jan Juhl (eds.). Les variations diasystématiques et leurs interdependences dans les langues romanes: Actes du Colloque DIA II à Copenhague. nov. 2012. Strabsbourg: Société de linguistique romane/ÉLiPhi, 2015. p. 19-21.

ALMEIDA, Edina Fátima; KAILER, Dircel Aparecida. O /R/ em coda silábica nas regiões sul e centro-oeste do Brasil, 2014. GSCP International Conference. Stockholm: Uppsala, 2015.

__ . Róticos em coda silábica interna nas regiões sul e centro-oeste do Brasil. In: BARDEL, Camilla; MEO, Anna De (Orgs.). Falando línguas românicas. Naples, 2016, p. 225-241.

ALMEIDA, Daniele Cristina de. Tratamento didático do apagamento e inserção da rótica em coda final de verbos. 2016. 120 f. Dissertação. (Mestrado Profissional em Letras) - Centro de Humanidades, Universidade Federal do Ceará, Fortaleza.

BORTONI-RICARDO, Stella Maris. Educação em língua materna: a sociolinguística na sala de aula. São Paulo: Parábola Editorial, 2004. 2005.

Nós cheguemu na escola, e agora?: sociolingüística \& educação. São Paulo: Parábola Editorial,

CALLOU, Dinah et al. O apagamento do R final no dialeto carioca: um estudo em tempo aparente e em tempo real. DELTA, São Paulo, v.14, n. Especial, p. 61- 72, 1998.

COMITÊ NACIONAL DO PROJETO ALIB (Brasil). Atlas linguístico do Brasil. Londrina: Ed. UEL, 2001.

GURJEL, Juliana Carlos Fernandes. Estratégias de ensino para a correção do apagamento da consoante " $R$ " na escrita de verbos no infinitivo de alunos do ensino fundamental. 2016. 91 f. Dissertação. (Mestrado Profissional em Letras) - Faculdade de Letras e Artes, Universidade do Estado do Rio Grande do Norte, Mossoró.

LABOV, William. Padrões sociolinguísticos. Tradução por Marcos Bagno. São Paulo: Parábola Editorial, 2008 [1972].

MOLLICA, M. C.; PAIVA, M. C. \& PINTO, I. Relação entre [l] $>[r]>[0]$ em grupos consonantais em português. In: Relatório final do projeto mecanismos funcionais do uso linguístico. Rio de Janeiro: UFRJ, 1989. 
MONARETTO, Valéria N. de Oliveira. O apagamento da vibrante pós-vocálica nas capitais do Sul do Brasil. Letras de Hoje, Porto Alegre, v. 35, n. 1, p. 275-284, mar. 2000.

NARO, Anthony Julius. Modelos quantitativos e tratamento estatístico. In: MOLLICA, Maria Cecília; BRAGA Maria Luíza (Orgs.). Introdução à sociolinguística: o tratamento da variação. 4.ed. São Paulo: Contexto 2012. p. 15-26.

RIBEIRO, Lorena Nascimento de Souza. O apagamento do $-R$ em posição de coda silábica: há influência da fala na escrita discente? 2013. 109 f. Dissertação (Mestrado) - Departamento de Ciências Humanas, Universidade do Estado da Bahia, Salvador.

SCHERRE, Maria Marta Pereira. Sobre a influência de três variáveis relacionadas na concordância nominal em português. In: SILVA, Giselle M. de Oliveira; (Orgs.). Padrões sociolinguísticos: análise de fenômenos variáveis do português falado na cidade do Rio de Janeiro. Rio de Janeiro: Editora da UFRJ, p.4162, 1996. Tempo Brasileiro.

THIOLLENT, Michel. Metodologia da pesquisa-ação. 10.ed. São Paulo: Cortez, 2000.

Recebido em 05/10/2019

e aprovado em 22/11/2019. 


\section{ANEXOS}

A: Cartas das Realizações do /R/
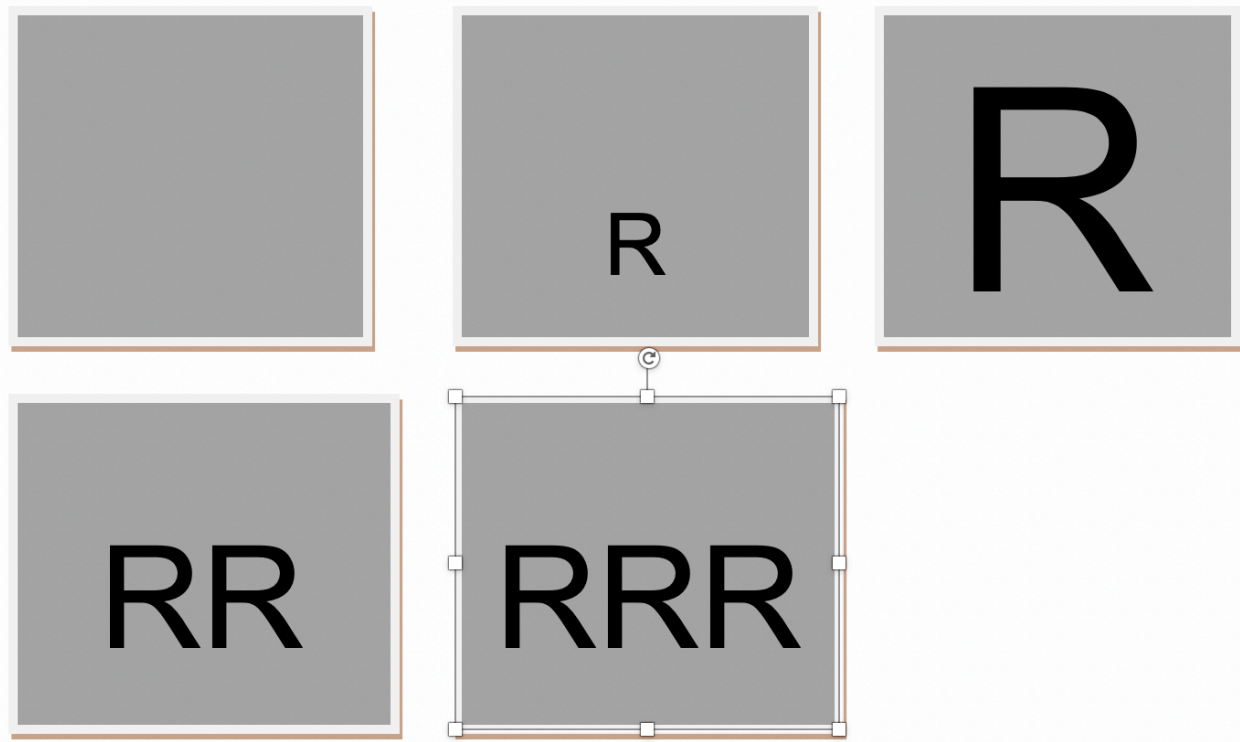
B: Cartelas para Bingo Ortográfico

\begin{tabular}{||c|c|c|c|c||}
\hline AMAR & SENHOR & MAR & PARTIR & PARTICIPAR \\
\hline PIOR & SUOR & SER & PEDIR & CARÁTER \\
\hline POR & PEGAR & IR & FALAR & FERVER \\
\hline
\end{tabular}

\begin{tabular}{||l|l|l|l|l||}
\hline SUOR & VIVER & MAR & PARTIR & CARÁTER \\
\hline PIOR & TER & SER & SENHOR & CANTOR \\
\hline POR & FERVER & VIR & FALAR & SENTAR \\
\hline
\end{tabular}

\begin{tabular}{||c|c|c|c|c||}
\hline FALAR & SENHOR & VIR & BEIJAR & NAMORAR \\
\hline VOAR & SUOR & SER & DOUTOR & CARÁTER \\
\hline TER & PEGAR & IR & PEDIR & CANTOR \\
\hline
\end{tabular}

